\title{
A COMBINED STRAIN ELEMENT TO FUNCTIONALLY GRADED STRUCTURES IN THERMAL ENVIRONMENT
}

\author{
HOANG LAN TON-ThaT ${ }^{a, b}$ \\ ${ }^{a}$ Ho Chi Minh City University of Architecture, Department of Civil Engineering, 196 Pasteur Street, District 3, \\ Ho Chi Minh City, Viet Nam \\ ${ }^{b}$ Ho Chi Minh City University of Technology and Education, Department of Civil Engineering, 01 Vo Van Ngan \\ Street, Thu Duc District, Ho Chi Minh City, Viet Nam \\ correspondence: lan.tonthathoang@uah.edu.vn; lantth.ncs@hcmute.edu.vn
}

\begin{abstract}
Functionally graded materials are commonly used in a thermal environment to change the properties of constituent materials. They inherently withstand high temperature gradients due to a low thermal conductivity, core ductility, low thermal expansion coefficient, and many others. It is essential to thoroughly study mechanical responses of them and to develop new effective approaches for an accurate prediction of solutions. In this paper, a new four-node quadrilateral element based on a combined strain strategy and first-order shear deformation theory is presented to achieve the behaviour of functionally graded plate/shell structures in a thermal environment. The main notion of the combined strain strategy is based on the combination of the membrane strain and the shear strain related to tying points as well as bending strain with respect to a cell-based smoothed finite element method. Due to the finite element analysis, the first-order shear deformation theory (FSDT) is simple to implement and apply for structures, but the shear correction factors are used to achieve the accuracy of solutions. The author assumes that the temperature distribution is uniform throughout the structure. The rule of mixtures is also considered to describe the variation of material compositions across the thickness. Many desirable characteristics and the enforcement of this element are verified and proved through various numerical examples. Numerical solutions and a comparison with other available solutions suggest that the procedure based on this new combined strain element is accurate and efficient.
\end{abstract}

Keywords: Combined strain, four-node quadrilateral element, first-order shear deformation theory, thermal environment.

\section{IntRODUCTION}

Functionally graded materials have been successfully applied in numerous fields of engineering. The material is usually made from a mixture of ceramic and metal and provides a continuous variation of material properties from the bottom surface to the top surface of the plate. The functionally graded materials have attracted more attention in thermal environment applications, such as spacecraft and nuclear tanks. The analytical solutions [1-4] are valuable in some certain cases, but in general, with complicated geometries or complex conditions like high temperatures in the thermal environment, they are often limited. Besides the analytical approaches, numerical methods are used in the structures analyses [5] 27]. Bui et al. [5] presented new numerical results of high temperature mechanical behaviour of heated functionally graded plates, emphasizing the high temperature effects on static bending deflections and natural frequencies. A displacement-based finite element formulation associated with the third-order shear deformation plate theory of Shi was thus developed. An improved four-node element based on twice-interpolation strategy was introduced by Ton-That et al. [6, 7] in linear and nonlinear analyses of composite plate/shell structures. Besides, thermal buckling analyses of functionally graded plates and cylindrical shells were investigated by S.Trabelsi et al. [12. In this reference, the finite element formulation based on a modified FSDT shell formulation was elaborated. A dynamic analysis of a functionally-graded carbon nanotube-reinforced plate and shell structures using a double directors finite shell element was firstly presented by A.Frikha et al. [13, 14. The governing equations were developed using a linear discrete double directors finite element model. The generalized differential quadrature method [15-18] was used to study the behaviour of functionally graded materials and laminated doubly curved shells and panels. The free vibration of beams made of imperfect functionally graded materials including porosities was investigated in [19] and the free vibration of functionally graded beams resting on two parameter elastic foundation was examined in [20] by M.Avcar et al. Due to the discrete singular convolution method, Ö.Civalek et al. [21 23] studied the behaviour of carbon nanotubes reinforced and functionally graded shells and plates respectively. 


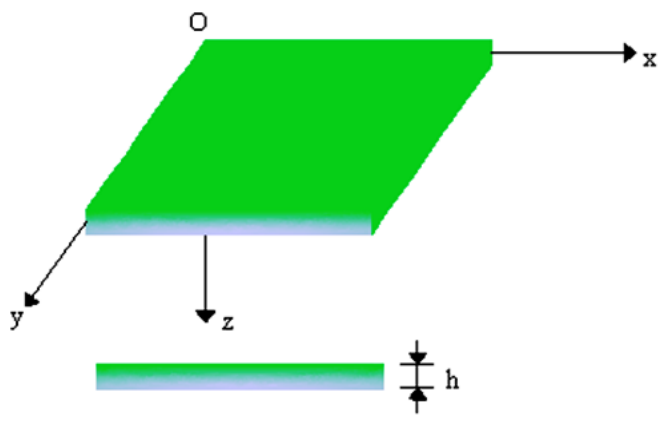

(A).

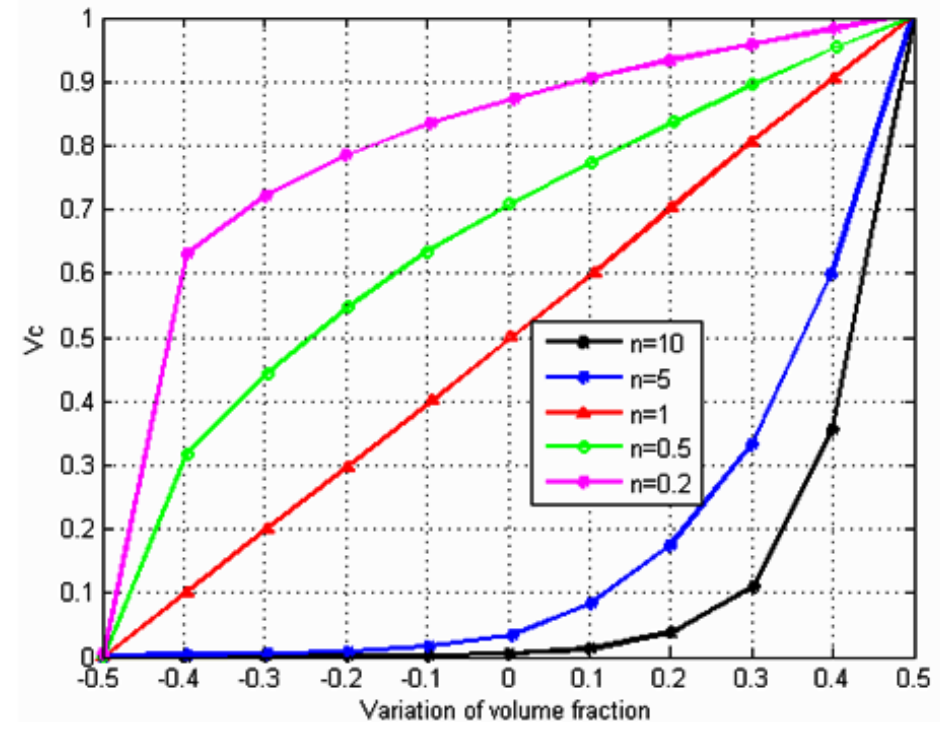

(в).

FIGURE 1. The functionally graded plate: a) in 3D space, b) with variation of volume fraction.

Moreover, based on the refined plate theory, some references [24 26] reviewed the mechanical behaviour of the functionally graded sandwich or functionally graded porous plates under various boundary conditions.

In this paper, a new four-node quadrilateral finite element related to the combined strain strategy is introduced. The main idea of this combined strain strategy is based on the combination of the membrane strain and shear strain related to tying points as well as bending strain with respect to cell-based smoothed finite element method. Some difficulties that arise in the standard FEM may be listed as follows: it requires large computer memory and computational time to obtain the desired results, the mapping or coordinate transformation is involved in the standard FEM, so its element is not allowed to be of arbitrary shape, the restriction on the shape bilinear isoparametric elements cannot be removed and the problem domain cannot be discretized in more flexible ways. This paper's element with the combined strain strategy that can does not suffer from the above mentioned difficulties is used to analyse the behaviour of functionally graded plate/shell structures in a thermal environment. Many desirable characteristics of the proposed element, such as accuracy, efficiency and removal of shear and membrane locking, are verified through several examples.

The article is organized into four Sections. In Sect. 2, formulation of this new element for functionally graded structures related to first-order shear deformation theory is presented. Several examples are subsequently given in Sect. 3. We end the paper with a summary and some concluding remarks in the last Section.

\section{Formulation of THE COMBinED STRAin ELEMENT FOR FUNCTIONALly GRADED MATERIAL}

\subsection{FunCtionally GRADED MATERIAL}

A functionally graded plate 28 is considered as shown in Figure 1 a with thickness $h$.

The volume fraction of the ceramic $\left(V_{c}\right)$ and metal $\left(V_{m}\right)$ are described in (1) and the variation of volume fraction for several volume fraction coefficients of a functionally graded plate using the power-law distribution is plotted by Figure $1 \mathrm{~b}$

$$
V_{c}=\left(\frac{z}{h}+\frac{1}{2}\right)^{n} \quad V_{m}=1-V_{c} \quad n \geq 0
$$

where $z$ is the thickness coordinate variable with $-h / 2 \leq z \leq h / 2$. And $c, m$ and $n$ represent the ceramic, metal constituents and the non-negative volume fraction gradient index, respectively. All values of $E, \rho, \nu$ and $\alpha$ that vary throughout the thickness of plate are formulated as below

$$
\begin{gathered}
E(z)=E_{m}+\left(E_{c}-E_{m}\right)\left(\frac{1}{2}+\frac{z}{h}\right)^{n} \\
\rho(z)=\rho_{m}+\left(\rho_{c}-\rho_{m}\right)\left(\frac{1}{2}+\frac{z}{h}\right)^{n}
\end{gathered}
$$




$$
\begin{aligned}
& \nu(z)=\nu_{m}+\left(\nu_{c}-\nu_{m}\right)\left(\frac{1}{2}+\frac{z}{h}\right)^{n} \\
& \alpha(z)=\alpha_{m}+\left(\alpha_{c}-\alpha_{m}\right)\left(\frac{1}{2}+\frac{z}{h}\right)^{n}
\end{aligned}
$$

The function of temperature $T(\mathrm{~K})$ can be expressed by following equation [1]

$$
P=P_{0}\left(P_{-1} T^{-1}+1+P_{1} T+P_{2} T^{2}+P_{3} T^{3}\right)
$$

where $T=T_{0}+\Delta T$ and $T_{0}=300 \mathrm{~K}$ (ambient or free stress temperature), $\Delta T$ is the temperature change, and $P_{0}, P_{-1}, P_{1}, P_{2}, P_{3}$ are the coefficients of temperature $T(\mathrm{~K})$, and are unique to each constituent.

\subsection{Formulation of the COMbined Strain ElEment}

In this section, the construction of the combined strain element is briefly given with respect to the first-order shear deformation theory

$$
\begin{aligned}
& u(x, y, z)=u_{0}(x, y)+z \theta_{y} \\
& v(x, y, z)=v_{0}(x, y)-z \theta_{x} \\
& w(x, y, z)=w_{0}(x, y)
\end{aligned}
$$

with $u_{0}, v_{0}, w_{0}$ being the displacements of a point located in the mid-surface, and $\theta_{x}, \theta_{y}$ are the rotations of the transverse normal, i.e. in the $\mathrm{z}$ direction, about the $x$ - as well as $y$ - axes, respectively. The membrane and bending strain vectors can be written as

$$
\boldsymbol{\epsilon}=\left[\begin{array}{c}
\epsilon_{x} \\
\epsilon_{y} \\
\gamma_{x y}
\end{array}\right]=\left[\begin{array}{c}
u_{0, x} \\
v_{0, y} \\
u_{0, y}+v_{0, x}
\end{array}\right]+z\left[\begin{array}{c}
\theta_{x} y, x \\
-\theta_{x, y} \\
\theta_{y, y}-\theta_{x, x}
\end{array}\right]=\epsilon^{m}+z \boldsymbol{\epsilon}^{b}
$$

and the shear strain vector is also given

$$
\boldsymbol{\epsilon}^{s}=\left[\begin{array}{c}
\epsilon_{x y} \\
\epsilon_{y z}
\end{array}\right]=\left[\begin{array}{c}
\theta_{y}+w_{0, x} \\
-\theta_{x}+w_{0, y}
\end{array}\right]
$$

Under Hooke's law, the constitutive equation is expressed as

$$
\begin{gathered}
\boldsymbol{\sigma}=\mathbf{D}_{m}(z)\left(\boldsymbol{\epsilon}^{m}+z \boldsymbol{\epsilon}^{b}-\boldsymbol{\epsilon}^{(T)}\right) \\
\boldsymbol{\tau}=\mathbf{D}_{s}(z)\left(\boldsymbol{\epsilon}^{s}\right)
\end{gathered}
$$

in which

$$
\begin{gathered}
\boldsymbol{\sigma}=\left[\begin{array}{ccc}
\sigma_{x} & \sigma_{y} & \sigma_{x y}
\end{array}\right]^{T} ; \quad \boldsymbol{\tau}=\left[\begin{array}{cc}
\tau_{y z} & \tau_{x z}
\end{array}\right]^{T} \\
\mathbf{D}_{m}(z)=\frac{E(z)}{1-v^{2}}\left[\begin{array}{ccc}
1 & v & 0 \\
v & 1 & 0 \\
0 & 0 & (1-v) / 2
\end{array}\right] \quad \mathbf{D}_{s}(z)=\frac{E(z)}{2(1+v)}\left[\begin{array}{cc}
1 & 0 \\
0 & 1
\end{array}\right] \\
\boldsymbol{\epsilon}^{(T)}=\left[\begin{array}{lll}
\boldsymbol{\epsilon}_{x}^{(T)} & \boldsymbol{\epsilon}_{y}^{(T)} & 0
\end{array}\right]^{T}=\left[\begin{array}{lll}
\alpha(z) \Delta T & \alpha(z) \Delta T & 0
\end{array}\right]^{T}
\end{gathered}
$$

The mid-surface of a four-node quadrilateral element is subdivided into four non-overlapping 3-node triangular domains defined by the vertices and the centre point ' 5 ' of the element as shown in Figure ??. The coordinates of the point ' 5 ' in the natural coordinate system are interpolated by $\mathbf{x}_{5}=\zeta_{1} \mathbf{x}_{1}+\zeta_{2} \mathbf{x}_{2}+\zeta_{3} \mathbf{x}_{3}+\zeta_{4} \mathbf{x}_{4}$ with

$$
\left[\begin{array}{l}
\zeta_{1} \\
\zeta_{2} \\
\zeta_{3} \\
\zeta_{4}
\end{array}\right]=\frac{1}{2} \frac{A_{234}}{A_{234}+A_{124}}\left[\begin{array}{c}
1 / 3 \\
1 / 3 \\
0 \\
1 / 3
\end{array}\right]+\frac{1}{2} \frac{A_{124}}{A_{234}+A_{124}}\left[\begin{array}{c}
0 \\
1 / 3 \\
1 / 3 \\
1 / 3
\end{array}\right]+\frac{1}{2} \frac{A_{134}}{A_{134}+A_{123}}\left[\begin{array}{c}
1 / 3 \\
1 / 3 \\
1 / 3 \\
0
\end{array}\right]+\frac{1}{2} \frac{A_{123}}{A_{134}+A_{123}}\left[\begin{array}{c}
1 / 3 \\
0 \\
1 / 3 \\
1 / 3
\end{array}\right]
$$

in which, $A_{234}, A_{124}, A_{134}$ and $A_{123}$ are the areas of triangles "234", "124", "134" and "123". From four non-overlapping triangular domains " 125 ", " 235 ", " 345 " and " 415 ", four tying points at four positions are determined as depicted in Figure 2b and clearly presented in [29]. 


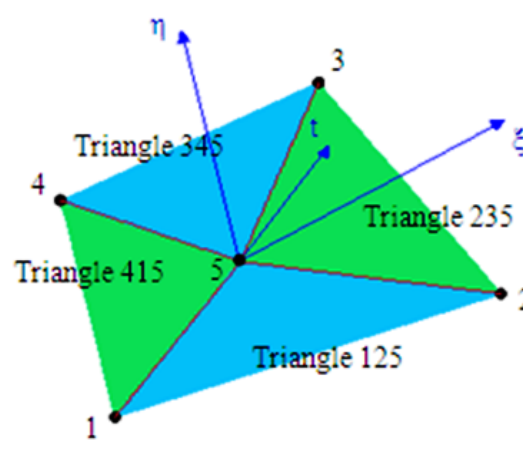

(A).

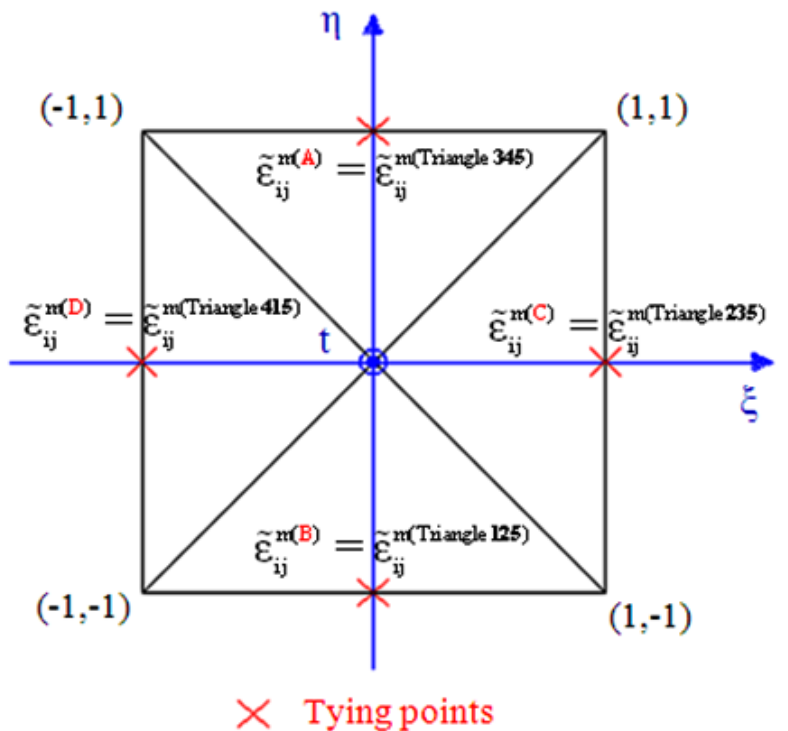

(B).

FiguRE 2. (a) Four triangular subdivisions, (b) Four tying points corresponding to these subdivisions.

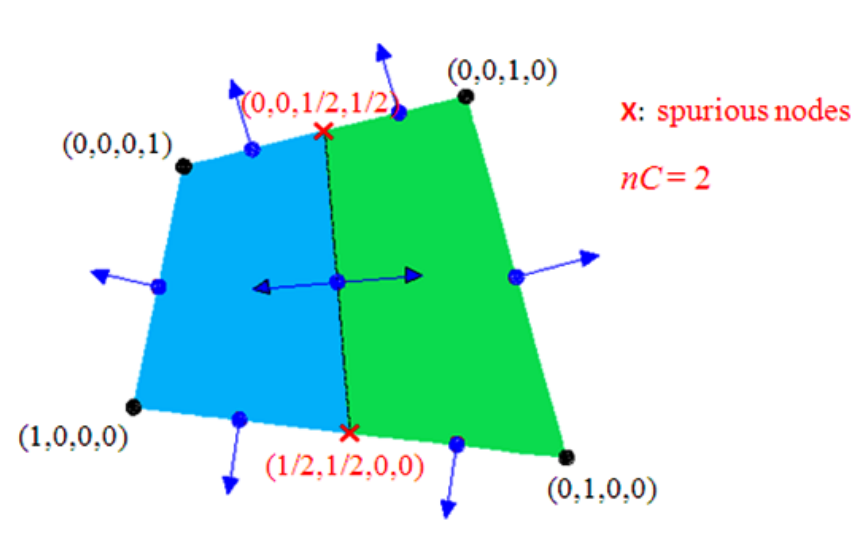

(A).

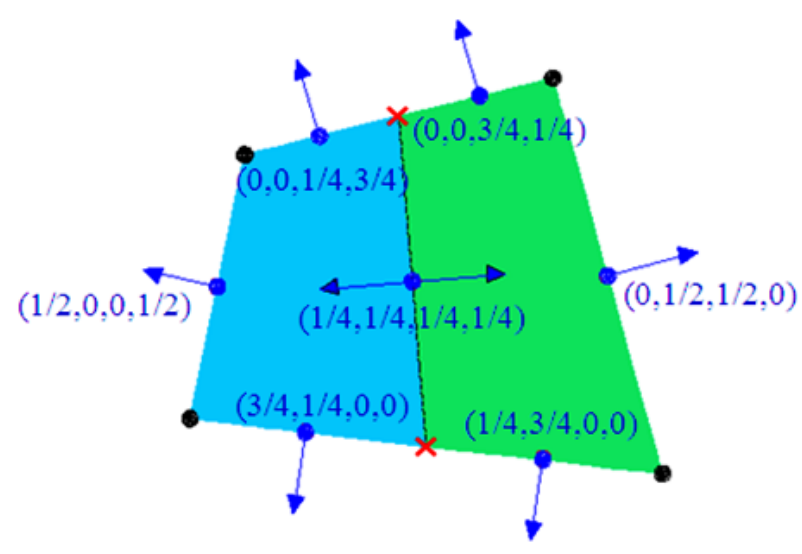

(c).

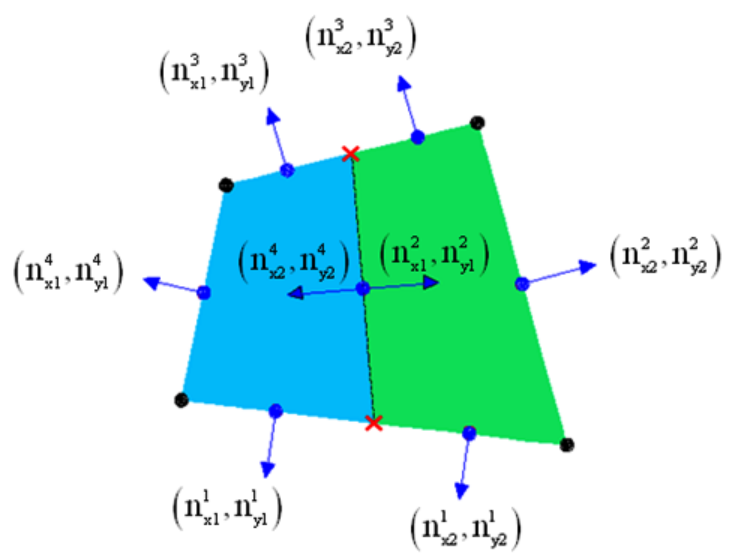

(B).

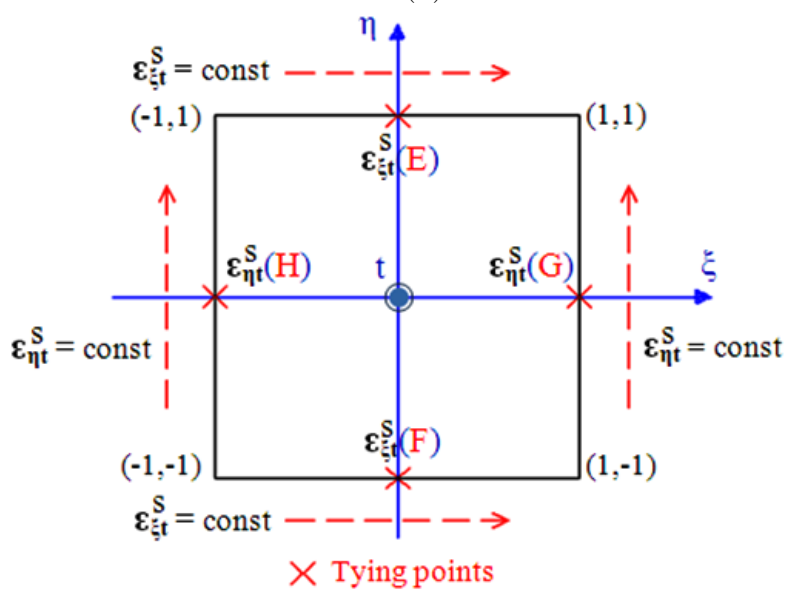

(D).

Figure 3. (a), (b) \& (c) nC smoothing cells with values of shape functions at nodes in format $\left(N_{1}, N_{2}, N_{3}, N_{4}\right)$, (d) Four tying points for calculating shear strain. 
Then the membrane strain is approximated as

$$
\begin{array}{r}
\boldsymbol{\epsilon}^{m}=\frac{1}{4}\left(\tilde{\boldsymbol{\epsilon}}^{m(A)}+\tilde{\boldsymbol{\epsilon}}^{m(B)}+\tilde{\boldsymbol{\epsilon}}^{m(C)}+\tilde{\boldsymbol{\epsilon}}^{m(D)}\right)+\frac{1}{2}\left(-\tilde{\boldsymbol{\epsilon}}^{m(D)}+\tilde{\boldsymbol{\epsilon}}^{m(C)}\right) \xi+\frac{1}{2}\left(-\tilde{\boldsymbol{\epsilon}}^{m(B)}+\tilde{\boldsymbol{\epsilon}}^{m(A)}\right) \eta= \\
\quad=\tilde{\boldsymbol{B}}_{m} \boldsymbol{q}_{m}=\boldsymbol{B}_{m} \boldsymbol{q}
\end{array}
$$

In which, $\tilde{\boldsymbol{\epsilon}}^{m(A)}, \tilde{\boldsymbol{\epsilon}}^{m(B)}, \tilde{\boldsymbol{\epsilon}}^{m(C)}, \tilde{\boldsymbol{\epsilon}}^{m(D)}$ are, respectively, the membrane strains of four triangular domains evaluated at the tying points.

The bending strain is smoothed by following [30 with Figure $3 \mathrm{a}, 3 \mathrm{~b} \& 3 \mathrm{c}$. The liaison bet-ween the nodal displacements and the smoothed bending strain field is written as

$$
\boldsymbol{\epsilon}^{b}=\sum_{i=1}^{n C} \tilde{\boldsymbol{B}}_{b i} \boldsymbol{q}_{b i}=\tilde{\boldsymbol{B}}_{b} \boldsymbol{q}_{b}=\boldsymbol{B}_{b} \boldsymbol{q} \quad \tilde{\boldsymbol{B}}_{b i}=\frac{1}{A_{C}} \int_{\Gamma_{c}}\left[\begin{array}{ccc}
0 & N_{i} n_{x} & 0 \\
0 & 0 & N_{i} n_{y} \\
0 & N_{i} n_{y} & N_{i} n_{x}
\end{array}\right] d \Gamma
$$

with $A_{c}$ and $\Gamma_{c}$ are the area and the boundary of the smoothing cell, respectively; $n_{x}$ and $n_{y}$ are the components of the vector normal to the boundary $\Gamma_{c}$.

Based on the assumed constant transverse shear strain conditions along the edges and using four tying points as shown in Figure 3d, the shear strain related to [31] can be expressed

$$
\boldsymbol{\epsilon}^{s}=\tilde{\boldsymbol{B}}_{s} \boldsymbol{q}_{s}=\boldsymbol{B}_{s} \boldsymbol{q} \quad \tilde{\boldsymbol{B}}_{s i}=\left[\begin{array}{cc}
x_{\xi} & y_{\xi} \\
x_{\eta} & y_{\eta}
\end{array}\right]^{-1}\left[\begin{array}{ccc}
N_{i, \xi} & b_{i}^{11} N_{i, \xi} & b_{i}^{12} N_{i, \xi} \\
N_{i, \eta} & b_{i}^{21} N_{i, \eta} & b_{i}^{22} N_{i, \eta}
\end{array}\right]
$$

where $b_{i}^{11}=\xi_{i} x_{\xi}^{M}, b_{i}^{12}=\xi_{i} y_{\xi}^{M}, b_{i}^{21}=\eta_{i} x_{\eta}^{L}$ and $b_{i}^{22}=\eta_{i} y_{\eta}^{L}$ in which $\xi_{i} \in\{-111-1\}, \eta_{i} \in\{-1-111\}$ and $(i, M, L) \in\{(1, F, H),(2, F, G),(2, E, G),(4, E, H)\}$ as well as

$$
N=\frac{1}{2}\left[\begin{array}{cccc}
1-\xi & 0 & 1+\xi & 0 \\
0 & 1-\eta & 0 & 1+\eta
\end{array}\right]
$$

The normal forces, bending moments and shear force can then be computed through the following relations

$$
\begin{gathered}
\overline{\boldsymbol{N}}=\left\{\begin{array}{ccc}
\tilde{N}_{x} & \tilde{N}_{y} & \tilde{N}_{x y}
\end{array}\right\}^{T}=\int_{-h / 2}^{h / 2}\left\{\begin{array}{ccc}
\sigma_{x} & \sigma_{y} & \sigma_{x y}
\end{array}\right\}^{T} d z=\int_{-h / 2}^{h / 2} \boldsymbol{D}_{m}(z)\left(\boldsymbol{\epsilon}^{m}+z \boldsymbol{\epsilon}^{b}-\boldsymbol{\epsilon}^{(T)}\right) d z \\
\overline{\boldsymbol{M}}=\left\{\begin{array}{ccc}
\tilde{M}_{x} & \tilde{M}_{y} & \tilde{M}_{x y}
\end{array}\right\}^{T}=\int_{-h / 2}^{h / 2}\left\{\begin{array}{lll}
\sigma_{x} & \sigma_{y} & \sigma_{x y}
\end{array}\right\}^{T} z d z=\int_{-h / 2}^{h / 2} \boldsymbol{D}_{m}(z)\left(\boldsymbol{\epsilon}^{m}+z \boldsymbol{\epsilon}^{b}-\boldsymbol{\epsilon}^{(T)}\right) z d z \\
\overline{\boldsymbol{Q}}=\left\{\begin{array}{lll}
\tilde{Q}_{y} & \tilde{Q}_{x}
\end{array}\right\}^{T}=\int_{-h / 2}^{h / 2}\left\{\begin{array}{ll}
\tau_{y z} & \tau_{x z}
\end{array}\right\}^{T} d z=\int_{-h / 2}^{h / 2} \boldsymbol{D}_{s}(z)\left(\boldsymbol{\epsilon}^{s}\right) d z
\end{gathered}
$$

Above equations can be presented in the matrix form

$$
\left\{\begin{array}{c}
\overline{\boldsymbol{N}} \\
\overline{\boldsymbol{M}} \\
\overline{\boldsymbol{Q}}
\end{array}\right\}=\left[\begin{array}{ccc}
\overline{\boldsymbol{A}} & \overline{\boldsymbol{B}} & \mathbf{0} \\
\overline{\boldsymbol{B}} & \overline{\boldsymbol{D}} & \mathbf{0} \\
\mathbf{0} & \mathbf{0} & \hat{\boldsymbol{A}}
\end{array}\right]\left\{\begin{array}{l}
\boldsymbol{\epsilon}^{m} \\
\boldsymbol{\epsilon}^{b} \\
\boldsymbol{\epsilon}^{s}
\end{array}\right\}-\left\{\begin{array}{c}
\overline{\boldsymbol{N}}^{(T)} \\
\overline{\boldsymbol{M}}^{(T)} \\
\mathbf{0}
\end{array}\right\}
$$

with

$$
\begin{aligned}
& (\overline{\boldsymbol{A}}, \quad \overline{\boldsymbol{B}}, \quad \overline{\boldsymbol{D}})=\int_{-h / 2}^{h / 2}\left(1, \quad z, \quad z^{2}\right) \boldsymbol{D}_{m}(z) d z \\
& (\hat{\boldsymbol{A}})=\int_{-h / 2}^{h / 2} \boldsymbol{D}_{s}(z) d z \\
& \left(\overline{\boldsymbol{N}}^{(T)}, \quad \overline{\boldsymbol{M}}^{(T)}\right)=\int_{-h / 2}^{h / 2} \boldsymbol{D}_{m}(z)(1, z)\left\{\begin{array}{lll}
1 & 1 & 0
\end{array}\right\}^{T} \alpha(z) \Delta T d z
\end{aligned}
$$

The total strain energy of a plate due to the normal forces, shear force and bending moments can be given by

$$
\begin{array}{r}
U=\frac{1}{2} \int_{V_{e}} \boldsymbol{\epsilon}^{T} \boldsymbol{\sigma} d V=\int_{S_{e}} \boldsymbol{u}^{T} \boldsymbol{f} d S=\frac{1}{2} \boldsymbol{q}^{T} \int_{S_{e}}\left(\boldsymbol{B}_{m}^{T} \overline{\boldsymbol{A}} \boldsymbol{B}_{m}+\boldsymbol{B}_{m}^{T} \overline{\boldsymbol{B}} \boldsymbol{B}_{b}+\boldsymbol{B}_{b}^{T} \overline{\boldsymbol{B}} \boldsymbol{B}_{m}+\boldsymbol{B}_{b}^{T} \overline{\boldsymbol{D}} \boldsymbol{B}_{b}+\boldsymbol{B}_{s}^{T} \hat{\boldsymbol{A}} \boldsymbol{B}_{s}\right) d S \boldsymbol{q}- \\
-\boldsymbol{q}^{T} \int_{S_{e}}\left(\boldsymbol{B}_{m}^{T} \overline{\boldsymbol{N}}^{(T)}+\boldsymbol{B}_{b}^{T} \overline{\boldsymbol{M}}^{(T)}\right) d S-\boldsymbol{q}^{T} \int_{S_{e}} \boldsymbol{N}^{T} \boldsymbol{f} d s+\frac{1}{2} \int_{S_{e}}\left(\boldsymbol{\epsilon}^{(T)}\right)^{T} \overline{\boldsymbol{A}} \boldsymbol{\epsilon}^{(T)} d S \quad(27)
\end{array}
$$




$$
U=\frac{1}{2} \boldsymbol{q}_{e}^{T} \boldsymbol{K}_{e} \boldsymbol{q}_{e}-\boldsymbol{q}_{e}^{T} \boldsymbol{F}_{e}^{(T)}-\boldsymbol{q}_{e}^{T} \boldsymbol{F}_{e}+\boldsymbol{C}^{(T)}=\boldsymbol{q}_{e}^{T}\left(\frac{1}{2} \boldsymbol{K}_{e} \boldsymbol{q}_{e}-\boldsymbol{F}_{e}^{(T)}-\boldsymbol{F}_{e}\right)+\boldsymbol{C}^{(T)}
$$

The kinetic energy is shown

$$
T=\frac{1}{2} \int_{V_{e}} \dot{\boldsymbol{u}}^{T} \boldsymbol{\rho}(z) \dot{\boldsymbol{u}} d V=\frac{1}{2} \dot{\boldsymbol{q}}^{T}\left\{\int_{V_{e}} \boldsymbol{N}^{T} \boldsymbol{L}^{T} \boldsymbol{\rho}(z) \boldsymbol{L} \boldsymbol{N} d V\right\} \dot{\boldsymbol{q}}=\frac{1}{2} \dot{\boldsymbol{q}}^{T} \boldsymbol{M}_{e} \dot{\boldsymbol{q}}
$$

in which $\boldsymbol{L}$ is clearly described as

$$
\boldsymbol{L}=\left[\begin{array}{ccccc}
1 & 0 & 0 & 0 & z \\
0 & 1 & 0 & -z & 0 \\
0 & 0 & 1 & 0 & 0
\end{array}\right]
$$

and the mass matrix of element is presented

$$
\boldsymbol{M}_{e}=\int_{V_{e}} \boldsymbol{N}^{T} \boldsymbol{L}^{T} \boldsymbol{\rho}(z) \boldsymbol{L} \boldsymbol{N} d V=\int_{S_{e}} \boldsymbol{N}^{T}\left(\int_{-h / 2}^{h / 2} \boldsymbol{\rho}(z) \boldsymbol{L}^{T} \boldsymbol{L} d z\right) \boldsymbol{N} d S
$$

For the bending analysis, the bending solutions can be obtained by solving the following equation

$$
\boldsymbol{K} \boldsymbol{d}=\boldsymbol{F}+\boldsymbol{F}^{(T)}
$$

The dynamic equations for solving the eigenvalue can be given as

$$
\left(\boldsymbol{K}-\omega^{2} \boldsymbol{M}\right) \boldsymbol{d}=0
$$

For shell structures, the drilling rotation is added in the local matrices. The null values of the stiffness corresponding to this drilling rotation are obtained by using approximate values. This value was equal to $10-3$ times the maximum diagonal value in the stiffness matrix of the element 32 .

\section{Numerical Results}

In this section, the numerical solutions for static bending and free vibration analyses of functionally graded structures in the thermal environment are presented. Unless specified otherwise, the shear correction factors are equal to $5 / 6$. Table. 1 gives the different material properties of functionally graded structures made of the ceramic $\left(\mathrm{Al}_{2} \mathrm{O}_{3}, \mathrm{Si}_{3} \mathrm{~N}_{4}, \mathrm{ZrO}_{2}\right)$ and the metal (SUS304) as written in [1, 3].

\subsection{Bending ANALYSis}

The author started examining the accuracy of the proposed element by comparing the achieved results with reference solutions related to other approaches available in literature. A fully simply supported FG plate $(a / b=1$ and $a / h=10)$ made of $\mathrm{Al} / \mathrm{Al}_{2} \mathrm{O}_{3}$ subjected to a uniform load $q$ is considered. The material properties $E_{m}=70 \mathrm{GPa}, E_{c}=380 \mathrm{GPa}, \nu_{m}=\nu_{c}=0.3$ are used and the maximum central deflection is normalized by $\bar{w}=\left[10 h^{3} E_{c} w(a / 2, b / 2)\right] / q a^{4}$. The comparisons of between the proposed method and others, such as Reddy's theory (RT) [33], the sinusoidal shear deformation theory (SSDT) [34, the hyperbolic shear deformation theory (HySDT) and Shi's theory (ST) [5] are presented in Table 2 for different values of $n$. The results of this paper show a good agreement with other reference solutions as depicted in Figure 4a. However, as the functionally graded plates become more and more metallic, larger deflections are obtained as compared to those more and more ceramic.

By considering the accuracy of the proposed element to analyse the functionally graded plates under a temperature environment, the temperature is set to be $T=300 \mathrm{~K}(\Delta T=0)$ and the same plate as the previous example is also studied, but now it is made of $\mathrm{Si}_{3} \mathrm{~N}_{4} / \mathrm{SUS} 304$. The properties related to this material can be seen in Table 1. The maximum central deflection is then normalized by $\bar{w}=\left[100 h^{3} E_{m} w(a / 2, b / 2)\right] /\left[12\left(1-\nu_{m}^{2}\right) q a^{4}\right]$ and compared with the analytical solutions given by [1]. With each value of $n$, a good agreement between the two results can be found, as presented in Table 3

To additionally explore the physical behaviour of functionally graded plates, the fully clamped Al2O3/SUS304 plate with $n=0.5$ and $a / b=1$ is considered by changing the thickness $(a / 5, a / 10, a / 20, a / 30 \& a / 50)$ and the temperature from $300 \mathrm{~K}$ to $1400 \mathrm{~K}$. The temperature-deflection curves are plotted in Figure 4b Generally, under high temperature environments, it clearly indicates a very important effect of the material combinations on the overall mechanical behaviour of functionally graded materials. The numerical results obtained are very interesting as the thinner plates yield larger deflections than the thicker ones. The mechanical deflections of all functionally graded plates increase for the higher temperature range. It means that when the functionally graded plates are subjected to higher temperature environments, larger deflections for all considered functionally graded plates can be reached. 


\begin{tabular}{|c|c|c|c|c|c|c|}
\hline Ceramic & $P(300 \mathrm{~K})$ & $P_{0}$ & $P_{-1}$ & $P_{1}$ & $P_{2}$ & $P_{3}$ \\
\hline \multicolumn{7}{|c|}{$\mathrm{Al}_{2} \mathrm{O}_{3}$} \\
\hline$E(\mathrm{~Pa})$ & $320.24 \mathrm{e} 9$ & $349.55 \mathrm{e} 9$ & 0 & $-3.853 \mathrm{e}-4$ & $4.027 \mathrm{e}-7$ & $-1.673 \mathrm{e}-10$ \\
\hline$\alpha(1 / \mathrm{K})$ & $7.203 \mathrm{e}-6$ & $6.8269 \mathrm{e}-6$ & 0 & $1.838 \mathrm{e}-4$ & 0 & 0 \\
\hline$\nu$ & 0.260 & 0.26 & 0 & 0 & 0 & 0 \\
\hline$\rho\left(\mathrm{kg} / \mathrm{m}^{3}\right)$ & 3800 & 3800 & 0 & 0 & 0 & 0 \\
\hline \multicolumn{7}{|c|}{$\mathrm{Si}_{3} \mathrm{~N}_{4}$} \\
\hline$E(\mathrm{~Pa})$ & $322.27 \mathrm{e} 9$ & $348.43 \mathrm{e} 9$ & 0 & $-3.070 \mathrm{e}-4$ & $2.160 \mathrm{e}-7$ & $-8.946 \mathrm{e}-11$ \\
\hline$\alpha(1 / \mathrm{K})$ & $7.475 \mathrm{e}-6$ & $5.8723 \mathrm{e}-6$ & 0 & $9.095 \mathrm{e}-4$ & 0 & 0 \\
\hline$\nu$ & 0.240 & 0.24 & 0 & 0 & 0 & 0 \\
\hline$\rho\left(\mathrm{kg} / \mathrm{m}^{3}\right)$ & 2370 & 2370 & 0 & 0 & 0 & 0 \\
\hline \multicolumn{7}{|c|}{$\mathrm{ZrO}_{2}$} \\
\hline$E(\mathrm{~Pa})$ & $168.06 \mathrm{e} 9$ & $244.27 \mathrm{e} 9$ & 0 & $-1.371 \mathrm{e}-3$ & $1.214 \mathrm{e}-6$ & $-3.681 \mathrm{e}-10$ \\
\hline$\alpha(1 / \mathrm{K})$ & $18.591 \mathrm{e}-6$ & $12.766 \mathrm{e}-6$ & 0 & $-1.491 \mathrm{e}-3$ & $1.006 \mathrm{e}-5$ & $-6.778 \mathrm{e}-11$ \\
\hline$\nu$ & 0.298 & 0.288 & 0 & $1.133 \mathrm{e}-4$ & & 0 \\
\hline$\rho\left(\mathrm{kg} / \mathrm{m}^{3}\right)$ & 3657 & 3657 & 0 & 0 & & 0 \\
\hline Metal & $P(300 \mathrm{~K})$ & $P_{0}$ & $P_{-1}$ & $P_{1}$ & $P_{2}$ & $P_{3}$ \\
\hline \multicolumn{7}{|c|}{ SUS304 } \\
\hline$E(\mathrm{~Pa})$ & $207.79 \mathrm{e} 9$ & $201.04 \mathrm{e} 9$ & 0 & $3.079 \mathrm{e}-4$ & $-6.534 \mathrm{e}-7$ & 0 \\
\hline$\alpha(1 / K)$ & $15.321 \mathrm{e}-6$ & $12.330 \mathrm{e}-6$ & 0 & $8.086 \mathrm{e}-4$ & 0 & 0 \\
\hline$\nu$ & 0.318 & 0.326 & 0 & $-2.002 \mathrm{e}-4$ & $3.797 \mathrm{e}-7$ & 0 \\
\hline$\rho\left(\mathrm{kg} / \mathrm{m}^{3}\right)$ & 8166 & 8166 & 0 & 0 & 0 & 0 \\
\hline
\end{tabular}

TABle 1. Temperature dependent coefficient of Young's modulus $E(\mathrm{~Pa})$, thermal expansion coefficient $\alpha(1 / \mathrm{K})$, Poisson's ratio $\nu$, mass density $\rho\left(\mathrm{kg} / \mathrm{m}^{3}\right)$ for various materials.

\begin{tabular}{ccccccc}
\hline \multirow{4}{*}{$n$} & \multicolumn{5}{c}{ Results } \\
\cline { 3 - 7 } & & RT & SSDT & HySDT & ST & Present \\
\cline { 2 - 7 } SSSS & Ceramic & 0.4665 & 0.4665 & 0.4665 & 0.4630 & 0.4673 \\
& 1 & 0.9421 & 0.9287 & 0.9421 & 0.9130 & 0.9304 \\
& 2 & 1.2227 & 1.1940 & 1.2228 & 1.2069 & 1.1929 \\
& 5 & 1.3530 & 1.3200 & 1.3533 & 1.3596 & 1.3144 \\
& 10 & 1.4646 & 1.4356 & 1.4653 & 1.4874 & 1.4225 \\
& Metal & 2.5328 & 2.5327 & 2.5327 & 2.5120 & 2.5351 \\
\hline
\end{tabular}

TABLE 2. Comparison of the dimensionless deflections of a functionally graded $\mathrm{Al} / \mathrm{Al}_{2} \mathrm{O}_{3}$ plate $(a / b=1, a / h=10)$ for different values of volume fraction exponent $n$.

\begin{tabular}{lcccc}
\hline Method & $n=0.5$ & $n=1$ & $n=5$ & $n=10$ \\
\hline Analytical approach based on HSDT & 0.3251 & 0.3430 & 0.3800 & 0.3960 \\
Present & 0.3342 & 0.3553 & 0.3905 & 0.4056 \\
\hline
\end{tabular}

TABLE 3. Comparison of the dimensionless deflections of a functionally graded $\mathrm{Si}_{3} \mathrm{~N}_{4} / \mathrm{SUS} 304$ plate $(a / b=1$, $a / h=10$ ) for different values of volume fraction exponent $n$ under ambient temperature. 


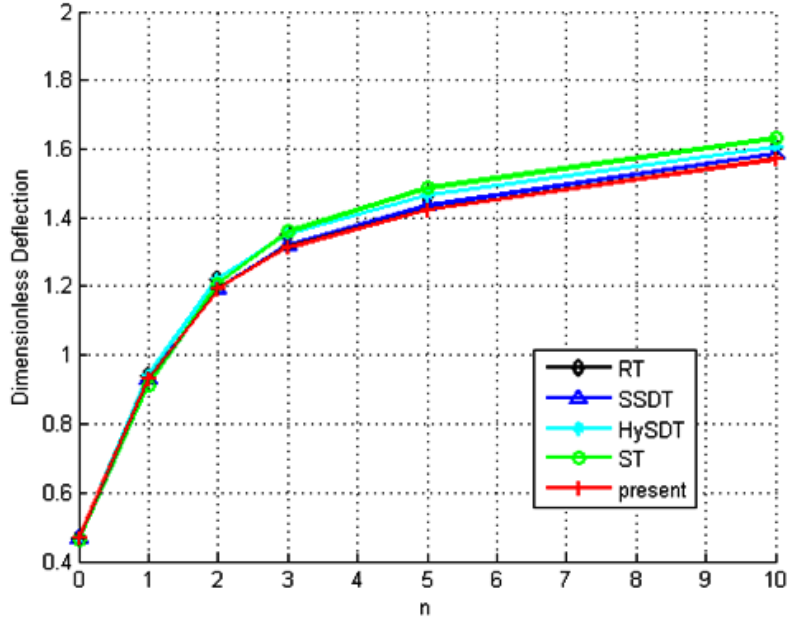

(A).

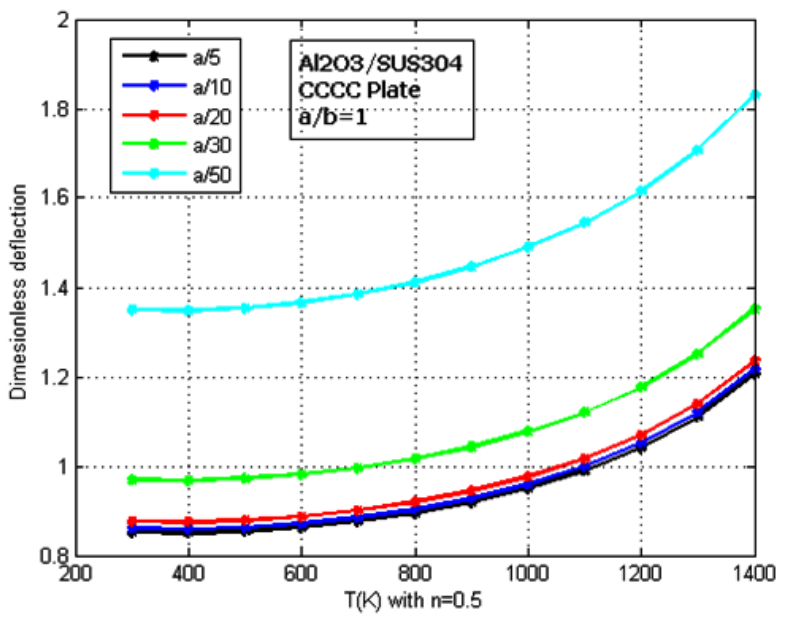

(B).

FiguRE 4. (a) The convergence of results for a fully simply supported functionally graded $\mathrm{Al} / \mathrm{Al}_{2} \mathrm{O}_{3}$ plate $(a / b=1$, $a / h=10)$, (b) Temperature-deflection curves for a fully clamped functionally graded $\mathrm{Al}_{2} \mathrm{O}_{3} / \mathrm{SUS} 304$ plate $(a / b=1$, $n=0.5)$.

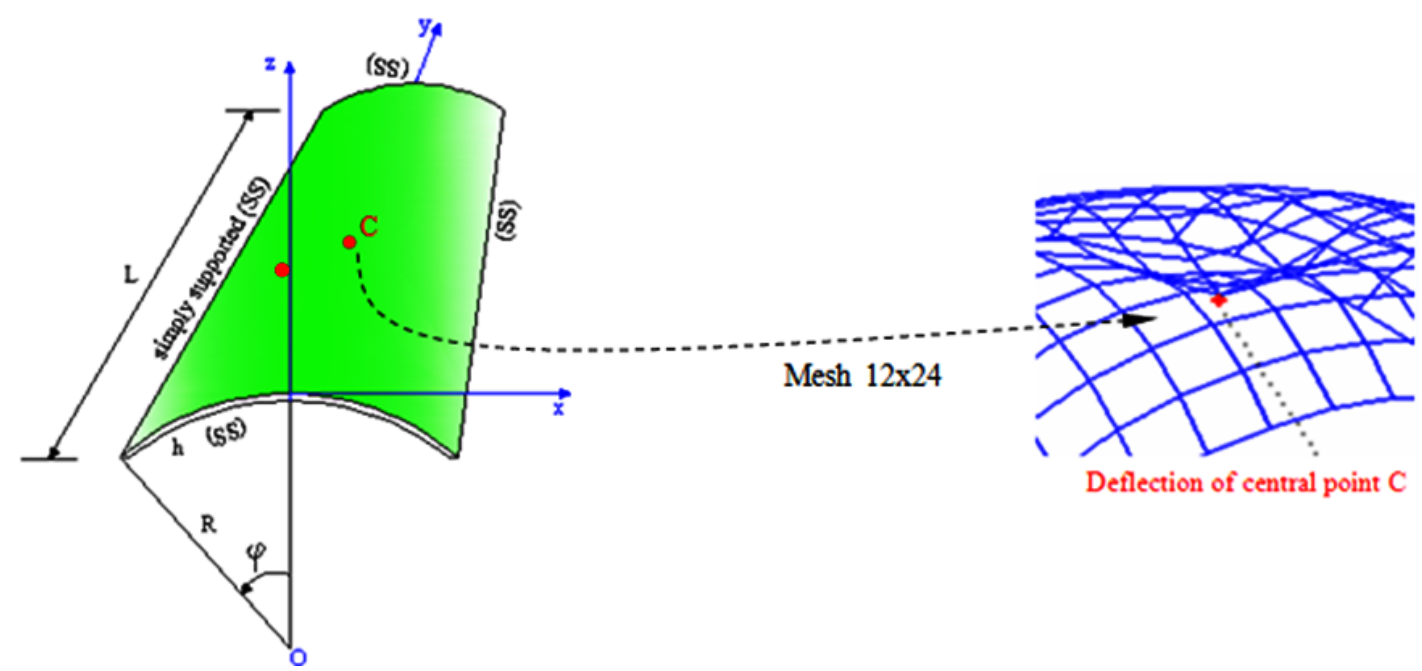

FIGURE 5. The geometry of a fully simply supported functionally graded $\mathrm{ZrO}_{2} / \mathrm{Al}$ cylindrical panel and the central deflection of the cylindrical panel.

The last example in this section is given with a fully simply supported $\mathrm{ZrO}_{2} / \mathrm{Al}$ cylindrical panel subjected to a uniform load $q=10^{6} \mathrm{~N} / \mathrm{m}^{2}$ as depicted in Figure 5. The material properties are also given as $E_{m}=70 \mathrm{GPa}$, $E_{c}=151 \mathrm{GPa}, \nu_{m}=\nu_{c}=0.3$. The geometric properties of this structure are denoted by $L=0.2 \mathrm{~m}, R=1 \mathrm{~m}$, and $\varphi=0.2 \mathrm{rad}$. The dimensionless central deflection is introduced by $\bar{w}=w_{\max } / h$ and the results of this paper are compared with the solutions based on the element-free kp-Ritz method of [35]. Table 4 presents the dimensionless central deflections with respect to the changes of ratio $S=R / h(50,100 \& 200)$ and three values of $n(0.5,1 \& 2)$.

Once again, the accuracy and efficiency of the combined strain element are proved by the very small errors shown in Table 4 between the results of this element and the results in 35 .

From this section, it can be concluded that the mechanical bending behaviour of the functionally graded structures is material dependent, mainly caused by the nonlinear thermal properties and material behaviour of constituent materials. In other words, not all the functionally graded structures in a high temperature environment act and react in the same manner, they, as observed numerically, behave differently from each other. Therefore, material combinations in terms of functionally graded materials are important and greatly affect the mechanical static bending behaviour of resultant functionally graded structures and their performance under high temperature conditions. Consequently, this phenomenon and behaviour of functionally graded materials may be important for the design and development of the functionally graded materials in engineering applications, especially for those that suffer tough temperature conditions. 


\begin{tabular}{ccccc}
\hline \multirow{2}{*}{$S=R / h$} & Method & \multicolumn{3}{c}{$\mathrm{n}$} \\
\cline { 3 - 5 } & & 0.5 & 1 & 2 \\
\hline \multirow{2}{*}{50} & The element-free kp-Ritz method & 0.0038 & 0.0043 & 0.0047 \\
& Present & 0.0038 & 0.0043 & 0.0048 \\
\hline \multirow{2}{*}{100} & The element-free kp-Ritz method & 0.0542 & 0.0607 & 0.0666 \\
& Present & 0.0542 & 0.0607 & 0.0666 \\
\hline \multirow{2}{*}{200} & The element-free kp-Ritz method & 0.6503 & 0.7283 & 0.8057 \\
& Present & 0.6422 & 0.7192 & 0.7954 \\
\hline
\end{tabular}

TABle 4. Comparison of the dimensionless deflections at a central point of a fully simply supported functionally graded $\mathrm{ZrO}_{2} / \mathrm{Al}$ cylindrical panel $(L=0.2 \mathrm{~m}, R=1 \mathrm{~m}, \varphi=0.2 \mathrm{rad})$ for different values of volume fraction exponent $n$ under an ambient temperature.

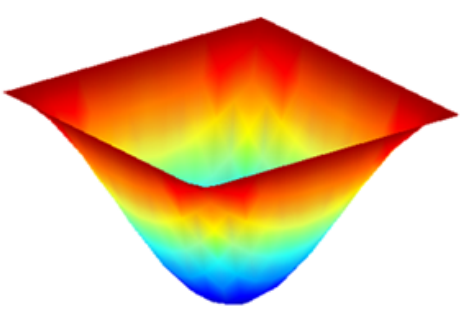

(A).

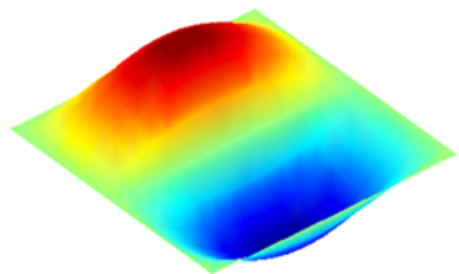

(в).

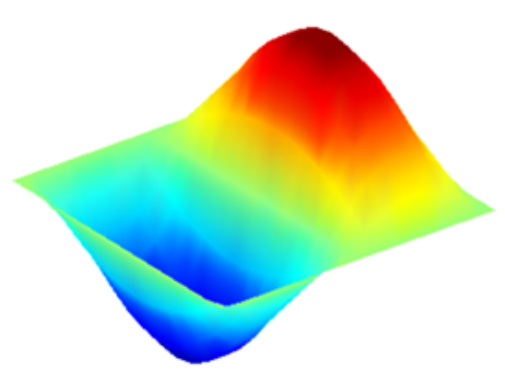

(c).

FiguRE 6 . The first three mode shapes of fully simply supported $\mathrm{Si}_{3} \mathrm{~N}_{4} / \mathrm{SUS} 304$ square plate.

\subsection{ViBRATION ANALYSIS}

The first example in this section is related to the fully simply supported square functionally graded plates and their natural frequencies in a thermal environment. Three types of materials are used in this study: $\mathrm{Si}_{3} \mathrm{~N}_{4} / \mathrm{SUS}_{304}$, $\mathrm{Al}_{2} \mathrm{O}_{3} / \mathrm{SUS} 304$ and $\mathrm{ZrO}_{2} / \mathrm{SUS} 304$. The geometrical parameters are set to be: length $a=b=0.2 \mathrm{~m}$, thickness $h=0.025 \mathrm{~m}$. The natural frequency results presented in the dimensionless values $\bar{\Omega}=\left(\omega a^{2} / h\right)\left[\rho_{m}\left(1-\nu^{2}\right) / E_{m}\right]^{1 / 2}$ with $E_{m}$ and $\rho_{m}$ are taken at $T=300 \mathrm{~K}$. Table 5 gives the comparison of first three modes of dimensionless frequencies of $\mathrm{Si}_{3} \mathrm{~N}_{4} / \mathrm{SUS} 304, \mathrm{Al}_{2} \mathrm{O}_{3} / \mathrm{SUS} 304$ and $\mathrm{ZrO}_{2} / \mathrm{SUS} 304$ square plates under different values of $n(0.5,1$ \& 2) among the proposed element and others related to two analytical solutions based on higher-order shear deformation theories [1, 3] and numerical solution based on the standard finite element method connected to the higher-order shear deformation theory [5]. As expected, the presented results show a good agreement with exact solutions. Although it only uses the first-order shear deformation theory, its results are almost identical to other results based on a higher-order shear deformation theory [1, 3, 55. Moreover, under the same conditions, the $\mathrm{Si}_{3} \mathrm{~N}_{4} /$ SUS304 square plate has the largest frequencies while $\mathrm{ZrO}_{2} / \mathrm{SUS} 304$ square plate provides the smallest values.

In order to further validate the accuracy of the combined strain element, especially for structures in high temperature environments, Table 6 presents a comparison of the fundamental frequency at high temperatures $T=400 \mathrm{~K}, 500 \mathrm{~K} \& 600 \mathrm{~K}$ of two types of materials, $\mathrm{Si}_{3} \mathrm{~N}_{4} / \mathrm{SUS} 304$ and $\mathrm{Al}_{2} \mathrm{O}_{3} / \mathrm{SUS} 304$, with fully clamped plates for three values of $n(0.5,1 \& 5)$ between the proposed element and analytical method based on Shi theory [1]. It can be seen that the frequencies at high temperatures achieved by the combined strain element are in close agreement with the analytical solutions [1.

Finally, the first three modes of a simply supported functionally graded $\mathrm{Si}_{3} \mathrm{~N}_{4} / \mathrm{SUS} 304$ square plate $(a=b=$ $0.2 \mathrm{~m}$ and $h=0.025 \mathrm{~m}$ ) are also depicted in Figure 6 The frequencies increase with increasing the temperature from $400 \mathrm{~K}$ upto $600 \mathrm{~K}$, but these frequencies decrease when the plates are more and more metallic.

\section{Conclusions}

9. In this work, an efficient numerical method based on the combined strain element is developed for modelling functionally graded structures in a thermal environment. The combination of the membrane strain and shear strain related to tying points and bending strain with respect to cell-based smoothed finite element method is established to build the proposed element. The numerical results show that the presented element can be used to analyse and predict the behaviour of functionally graded plate/shell structures in a thermal environment. In each case of the study with, the achieved results are found to agree well with other analytical results, or with 


\begin{tabular}{|c|c|c|c|c|c|c|}
\hline$n$ & Material & Mode & [1] & 3 & [5] & Present \\
\hline \multirow{9}{*}{0.5} & \multirow{3}{*}{$\mathrm{Si}_{3} \mathrm{~N}_{4} / \mathrm{SUS} 304$} & 1 & 8.675 & 8.646 & 8.554 & 8.555 \\
\hline & & 2 & 20.262 & 20.080 & 20.559 & 20.849 \\
\hline & & 3 & 30.359 & 29.908 & 31.088 & 31.514 \\
\hline & \multirow{3}{*}{$\mathrm{Al}_{2} \mathrm{O}_{3} / \mathrm{SUS} 304$} & 1 & & 7.803 & 7.805 & 7.759 \\
\hline & & 2 & & 18.253 & 19.003 & 18.892 \\
\hline & & 3 & & 27.569 & 28.018 & 28.538 \\
\hline & \multirow{3}{*}{$\mathrm{ZrO}_{2} / \mathrm{SUS} 304$} & 1 & & 6.368 & 6.406 & 6.418 \\
\hline & & 2 & & 14.824 & 15.119 & 15.567 \\
\hline & & 3 & & 24.570 & 24.719 & 23.453 \\
\hline \multirow{9}{*}{1} & \multirow{3}{*}{$\mathrm{Si}_{3} \mathrm{~N}_{4} / \mathrm{SUS} 304$} & 1 & 7.555 & 7.599 & 7.487 & 7.502 \\
\hline & & 2 & 17.649 & 17.705 & 17.987 & 18.286 \\
\hline & & 3 & 26.606 & 26.727 & 27.209 & 27.643 \\
\hline & \multirow{3}{*}{$\mathrm{Al}_{2} \mathrm{O}_{3} / \mathrm{SUS} 304$} & 1 & & 7.114 & 6.997 & 7.058 \\
\hline & & 2 & & 16.633 & 16.518 & 17.185 \\
\hline & & 3 & & 24.700 & 25.433 & 25.958 \\
\hline & \multirow{3}{*}{$\mathrm{ZrO}_{2} / \mathrm{SUS} 304$} & 1 & & 6.037 & 6.075 & 6.080 \\
\hline & & 2 & & 14.014 & 14.544 & 14.760 \\
\hline & & 3 & & 21.456 & 21.582 & 22.250 \\
\hline \multirow{9}{*}{2} & \multirow{3}{*}{$\mathrm{Si}_{3} \mathrm{~N}_{4} / \mathrm{SUS} 304$} & 1 & 6.777 & 6.825 & 6.705 & 6.737 \\
\hline & & 2 & 15.809 & 15.947 & 16.083 & 16.413 \\
\hline & & 3 & 23.806 & 24.147 & 24.326 & 24.803 \\
\hline & \multirow{3}{*}{$\mathrm{Al}_{2} \mathrm{O}_{3} / \mathrm{SUS} 304$} & 1 & & 6.563 & 6.519 & 6.511 \\
\hline & & 2 & & 15.323 & 15.833 & 15.841 \\
\hline & & 3 & & 23.048 & 23.346 & 23.916 \\
\hline & \multirow{3}{*}{$\mathrm{ZrO}_{2} / \mathrm{SUS} 304$} & 1 & & 5.753 & 5.796 & 5.794 \\
\hline & & 2 & & 13.294 & 13.898 & 14.081 \\
\hline & & 3 & & 20.247 & 20.636 & 21.243 \\
\hline
\end{tabular}

TABLE 5. The comparison of first three modes of dimensionless frequencies of fully simply supported functionally graded plates under ambient temperature.

\begin{tabular}{lccccccc}
\hline \multirow{2}{*}{$n$} & \multirow{2}{*}{ Mode 1} & \multicolumn{3}{c}{$\mathrm{Si}_{3} \mathrm{~N}_{4} / \mathrm{SUS} 304$} & \multicolumn{3}{c}{$\mathrm{Al}_{2} \mathrm{O}_{3} / \mathrm{SUS} 304$} \\
\cline { 3 - 8 } & & $400 \mathrm{~K}$ & $500 \mathrm{~K}$ & $600 \mathrm{~K}$ & $400 \mathrm{~K}$ & $500 \mathrm{~K}$ & $600 \mathrm{~K}$ \\
\hline \multirow{2}{*}{0.5} & Analytical solution & 15.938 & 15.468 & 14.939 & 14.384 & 14.003 & 13.592 \\
& Present & 14.966 & 14.990 & 15.083 & 13.568 & 13.611 & 13.727 \\
\hline \multirow{2}{*}{1} & Analytical solution & 13.915 & 13.426 & 12.941 & 13.025 & 12.631 & 12.188 \\
& Present & 13.121 & 13.133 & 13.190 & 12.339 & 12.365 & 12.441 \\
\hline \multirow{2}{*}{5} & Analytical solution & 11.175 & 10.749 & 10.242 & 10.965 & 10.556 & 10.073 \\
& Present & 10.672 & 10.679 & 10.694 & 10.533 & 10.539 & 10.564 \\
\hline
\end{tabular}

TABLE 6. Dimensionless frequencies of fully clamped functionally graded plates $(a / b=1, a / h=10)$ in a high temperature. 
other numerical methods. Based on this element, the presented numerical solutions offer more stable than others and the applicability of proposed element has been clearly shown as above section. The present formulation is general and can be extended to other problems, especially those in high temperature environments. The paper also helps to supplement knowledge for engineers in the design process. The functionally graded materials, where the excellent characteristics of ceramic in heat and corrosive resistances combine with the ability to absorb energy and plastically deform and toughness of metals, are outstanding advanced materials that can withstand large mechanical loads under a high temperature. Mechanical information might also be helpful to the designers or researchers in the appropriate selection of functionally graded materials for specific purposes, for instance, a right selection of the functionally graded materials for the right conditions such as structures to be working under high temperature conditions is of course a great benefit in practice.

\section{REFERENCES}

[1] N. Wattanasakulpong, G. B. Prusty, D. W. Kelly. Free and forced vibration analysis using improved third-order shear deformation theory for functionally graded plates under high temperature loading. Journal of Sandwich Structures \& Materials 15(5):583 - 606, 2013. DOI:10.1177/1099636213495751.

[2] N. Wattanasakulpong, B. Gangadhara Prusty, D. W. Kelly. Thermal buckling and elastic vibration of third-order shear deformable functionally graded beams. International Journal of Mechanical Sciences 53(9):734 - $743,2011$. DOI:10.1016/j.ijmecsci.2011.06.005

[3] X.-L. Huang, H.-S. Shen. Nonlinear vibration and dynamic response of functionally graded plates in thermal environments. International Journal of Solids and Structures 41(9):2403 - 2427, 2004. DOI:10.1016/j.ijsolstr.2003.11.012

[4] J. Yang, H.-S. Shen. Nonlinear bending analysis of shear deformable functionally graded plates subjected to thermo-mechanical loads under various boundary conditions. Composites Part B: Engineering 34(2):103 - 115, 2003. DOI:10.1016/S1359-8368(02)00083-5.

[5] T. Q. Bui, T. V. Do, L. H. T. Ton, et al. On the high temperature mechanical behaviors analysis of heated functionally graded plates using FEM and a new third-order shear deformation plate theory. Composites Part B: Engineering 92:218 - 241, 2016. DOI:10.1016/j.compositesb.2016.02.048.

[6] H. L. Ton-That, H. Nguyen-Van, T. Chau-Dinh. An improved four-node element for analysis of composite plate/shell structures based on twice interpolation strategy. International Journal of Computational Methods 17(06):1950020, 2020. DOI:10.1142/S0219876219500208

[7] H. L. Ton That, H. Nguyen-Van, T. Chau-Dinh. Nonlinear bending analysis of functionally graded plates using sq4t elements based on twice interpolation strategy. Journal of Applied and Computational Mechanics 6(1):125 - 136, 2020. DOI:10.22055/jacm.2019.29270.1577.

[8] L. T. That-Hoang, H. Nguyen-Van, T. Chau-Dinh, C. Huynh-Van. Enhancement to four-node quadrilateral plate elements by using cell-based smoothed strains and higher-order shear deformation theory for nonlinear analysis of composite structures. Journal of Sandwich Structures \& Materials 22(7):2302 - 2329, 2020. DOI:10.1177/1099636218797982

[9] H. Nguyen-Van, H. L. Ton-That, T. Chau-Dinh, N. D. Dao. Nonlinear static bending analysis of functionally graded plates using misq24 elements with drilling rotations. In H. Nguyen-Xuan, P. Phung-Van, T. Rabczuk (eds.), Proceedings of the International Conference on Advances in Computational Mechanics 2017, pp. 461 - 475. Springer Singapore, Singapore, 2018. DOI:10.1007/978-981-10-7149-2\_31.

[10] H. L. Ton-That. Finite element analysis of functionally graded skew plates in thermal environment based on the new third-order shear deformation theory. Journal of Applied and Computational Mechanics 6(4):1044 - $1057,2020$. DOI:10.22055/jacm.2019.31508.1881.

[11] M. Bayat, I. Alarifi, A. Khalili, et al. Thermo-mechanical contact problems and elastic behaviour of single and double sides functionally graded brake disks with temperature-dependent material properties. Scientific Reports 9:15317, 2019. DOI:10.1038/s41598-019-51450-z.

[12] S. Trabelsi, A. Frikha, S. Zghal, D. Fakhreddine. A modified FSDT-based four nodes finite shell element for thermal buckling analysis of functionally graded plates and cylindrical shells. Engineering Structures 178:444 - 459, 2018. DOI:10.1016/j.engstruct.2018.10.047.

[13] A. Frikha, S. Zghal, F. Dammak. Dynamic analysis of functionally graded carbon nanotubes-reinforced plate and shell structures using a double directors finite shell element. Aerospace Science and Technology 78:438 - 451, 2018. DOI:10.1016/j.ast.2018.04.048

[14] S. Zghal, A. Frikha, D. Fakhreddine. Mechanical buckling analysis of functionally graded power-based and carbon nanotubes-reinforced composite plates and curved panels. Composites Part B: Engineering 150:165 - 183, 2018. DOI:10.1016/j.compositesb.2018.05.037.

[15] F. Tornabene, N. Fantuzzi, M. Bacciocchi, E. Viola. Effect of agglomeration on the natural frequencies of functionally graded carbon nanotube-reinforced laminated composite doubly-curved shells. Composites Part B: Engineering 89:187 - 218, 2016. DOI:10.1016/j.compositesb.2015.11.016 
[16] F. Tornabene, N. Fantuzzi, E. Viola. Stress and strain recovery for functionally graded free-form and doubly-curved sandwich shells using higher-order equivalent single layer theory. Composite Structures 119:67 - 89, 2015. DOI:10.1016/j.compstruct.2014.08.005

[17] F. Tornabene, A. Liverani, G. Caligiana. FGM and laminated doubly curved shells and panels of revolution with a free-form meridian: A 2-D GDQ solution for free vibrations. International Journal of Mechanical Sciences 53:446 470, 2011. DOI:10.1016/j.ijmecsci.2011.03.007

[18] F. Tornabene. Free vibration analysis of functionally graded conical, cylindrical shell and annular plate structures with a four-parameter power-law distribution. Computer Methods in Applied Mechanics and Engineering 198:2911 2935, 2009. DOI:10.1016/j.cma.2009.04.011

[19] M. Avcar. Free vibration of imperfect sigmoid and power law functionally graded beams. Steel and Composite Structures 30:603 - 615, 2019. DOI:10.12989/scs.2019.30.6.603

[20] M. Avcar, W. K. M. Mohammed. Free vibration of functionally graded beams resting on Winkler-Pasternak foundation. Arabian Journal of Geosciences 11:232, 2018. DOI:10.1007/s12517-018-3579-2

[21] Ö. Civalek, M. Acar. Discrete singular convolution method for the analysis of Mindlin plates on elastic foundations. International Journal of Pressure Vessels and Piping 84:527 - 535, 2007. DOI:10.1016/j.ijpvp.2007.07.001.

[22] Ö. Civalek. Free vibration of carbon nanotubes reinforced (CNTR) and functionally graded shells and plates based on FSDT via discrete singular convolution method. Composites Part B: Engineering 111:45 - 59, 2017. DOI:10.1016/j.compositesb.2016.11.030

[23] Ö. Civalek, M. Avcar. Free vibration and buckling analyses of CNT reinforced laminated non-rectangular plates by discrete singular convolution method. Engineering with Computers pp. 1 - 33, 2020. DOI:10.1007/s00366-020-01168-8

[24] A. Menasria, A. Kaci, A. A. Bousahla, et al. A four-unknown refined plate theory for dynamic analysis of FG-sandwich plates under various boundary conditions. Steel and Composite Structures 36:355 - 367, 2020. DOI:10.12989/scs.2020.36.3.355

[25] M. Rahmani, K. Abdelhakim, A. Bousahla, et al. Influence of boundary conditions on the bending and free vibration behavior of FGM sandwich plates using a four-unknown refined integral plate theory. Computers and Concrete 25:225 - 244, 2020. DOI:10.12989/cac.2020.25.3.225.

[26] A. Zine, A. A. Bousahla, F. Bourada, et al. Bending analysis of functionally graded porous plates via a refined shear deformation theory. Computers and Concrete 26:63 - 74, 2020. DOI:10.12989/cac.2020.26.1.063.

[27] H. L. Ton-That. Improvement on eight-node quadrilateral element (IQ8) using twice-interpolation strategy for linear elastic fracture mechanics. Engineering Solid Mechanics 8:323 - 336, 2020. DOI:10.5267/j.esm.2020.3.005

[28] D. K. Jha, T. Kant, R. K. Singh. A critical review of recent research on functionally graded plates. Composite Structures 96:833 - 849, 2013. DOI:10.1016/j.compstruct.2012.09.001

[29] K. Yeongbin, P.-S. Lee, K.-J. Bathe. The MITC4+ shell element and its performance. Computers \& Structures 169:57 - 68, 2016. DOI:10.1016/j.compstruc.2016.03.002

[30] H. Nguyen-Van, N. Mai-Duy, T. Tran-Cong. A simple and accurate four-node quadrilateral element using stabilized nodal integration for laminated plates. Computers, Materials \& Continua 6:159 - 176, 2007. DOI:10.3970/cmc.2007.006.159.

[31] K.-J. Bathe, E. N. Dvorkin. A formulation of general shell elements-the use of mixed interpolation of tensorial components. International journal for numerical methods in engineering 22:697 - 722, 1986. DOI:10.1002/nme.1620220312.

[32] D. D. Fox, J. C. Simo. A drill rotation formulation for geometrically exact shells. Computer Methods in Applied Mechanics and Engineering 98:329 - 343, 1992. DOI:10.1016/0045-7825(92)90002-2.

[33] J. N. Reddy. Analysis of functionally graded plates. International Journal for numerical methods in engineering 47:663 - 684, 2000. DOI:10.1002/(SICI)1097-0207(20000110/30)47:1/3<663::AID-NME787>3.0.CO;2-8

[34] A. M. Zenkour. Generalized shear deformation theory for bending analysis of functionally graded plates. Applied Mathematical Modelling 30:67 - 84, 2006. DOI:10.1016/j.apm.2005.03.009

[35] X. Zhao, Y. Lee, K. Liew. Thermoelastic and vibration analysis of functionally graded cylindrical shells. International Journal of Mechanical Sciences 51:694 - 707, 2009. DOI:10.1016/j.ijmecsci.2009.08.001. 